\title{
Evaluasi Sistem Dapodikmen Dengan Pendekatan Utility System Pada Sekolah Menengah Atas Negeri Kota Palembang
}

\author{
Raden Ayu Indriansari, Darius Antoni \& Linda Atika \\ Universitas Bina Darma \\ Email: radenayuindriansari@gmail.com
}

\begin{abstract}
Dapodikmen system has not yet reached its accurately and effective utilization.. The results of observation and interview done to school operators in some high schools in Palembang show that there are different factors which determine the effectiveness of the system, for example, the content of information, ease of access and availability of the system which often has not been in accordance with the users' needs. One approach used to evaluate the effectiveness of the system is the System Utility. The approach by Kendall \& Kendall, 2007 (in Martoyo, 2015:638) review the success of the system implementation from six points of view, namely possession, goal, place, form, time and actualization utility. This approach is included in the category of system effectiveness evaluation viewed from the user's expectations. The results of this study demonstrate that of the aspect of variable utility and value of the Dapodikmen system is 4, 2636. This concludes that the availability of the system in high schools in Palembang city is effective.
\end{abstract}

Keywords: dapodikmen, system utility, possession, goal, place, form, time, actualization

\section{Pendahuluan}

Identifikasi masalah dalam penelitian ini adalah berdasarkan persepsi pengguna bahwa sistem DAPODIKMEN belum akurat dari sisi kandungan informasi dan kelengkapan isi data sekolah, Sistem DAPODIKMEN dari sisi kemudahan akses dan ketersediaan sistem kurang efektif dan belum pernah dilakukan evaluasi pengukuran tingkat persepsi pengguna sistem DAPODIKMEN oleh operator sekolah SMA yang ada di kota Palembang. Batasan masalah dalam penelitian ini membangun kerangka penilaian persepsi pengguna sistem DAPODIKMEN berdasarkan konsep system utility, menerapkan kerangka penilaian persepsi pengguna sistem DAPODIKMEN pada operator sekolah menengah atas negeri kota palembang serta mengukur dan mengevaluasi tingkat persepsi pengguna sistem DAPODIKMEN dengan menyebarkan kuisioner kepada pengguna sistem.

Penelitian ini mengkaji ruang lingkup permasalahan, bagaimana evaluasi sistem DAPODIKMEN dengan membangun kerangka penilaian berdasarkan konsep system utility untuk mengukur tingkat persepsi pengguna sistem DAPODIKMEN pada sekolah menengah atas negeri kota palembang.

Tujuan penelitian ini difokuskan pada kajian evaluasi sistem DAPODIKMEN berdasarkan konsep kerangka penilaian dengan pendekatan system utility untuk mengukur tingkat persepsi pengguna sistem DAPODIKMEN sehingga pada implementasinya diharapkan dapat membantu dalam penyediaan data sekolah yang lengkap, akurat dan mudah diakses sebagai bahan penyusunan kebijakan program, evaluasi, dan perencanaan.

Adapun manfaat penelitian ini adalah dapat mengetahui seberapa besar tingkat persepsi pengguna sistem DAPODIKMEN yang ada di Sekolah Menengah Atas Negeri Kota Palembang, dengan mengevaluasi sistem DAPODIKMEN dengan pendekatan system utility pada Sekolah Menengah Atas Negeri Kota Palembang nantinya bisa dijadikan sebagai bahan 
referensi atau masukkan dalam proses penyusunan kebijakan program, evaluasi, dan perencanaan pengembangan sistem.

\section{Tinjauan Literatur}

Aplikasi dapodikmen merupakan perkembangan dari aplikasi PAS. Dapodikmen merupakan aplikasi yang digunakan untuk melengkapi data PAS yang menyesuaikan dengan struktur data Dapodikmen dengan tujuan mendapatkan data yang akurat dan lengkap. Aplikasi Sistem Dapodikmen terbagi menjadi tiga bagian yaitu aplikasi Front End, aplikasi Sinkronisasi dan aplikasi Back End. Dapodik adalah aplikasi managemen sekolah yang mengelola ketenagaan (PTK), kesiswaan (peserta didik), sarpras (sarana prasarana), pembelajaran dan lainnya. Bagi operator sekolah atau yang dikenal dengan sebutan OPS istilah Dapodik bukan lagi hal yang aneh. Setiap tahun ajaran baru akan disuguhkan dengan aplikasi versi baru yang menandakan setiap OPS siap bekerja lagi menyajikan data yang sevalid mungkin. Karena harus menyajikan data sevalid mungkin dan berkaitan erat dengan nasib sekolah sekaligus nasib para guru terutama para penerima tunjangan sertifikasi. Namun, meskipun sudah sering mengerjakan dapodik ternyata masih ada saja OPS yang kebingungan dengan berbagai macam masalah yang dihadapi.

Ketersediaan data dan informasi pada sistem Dapodik dirasakan kurang akurat dan efektif. Dari hasil observasi dan wawancara yang di lakukan pada OPS sekolah di SMA Negeri 13 Palembang ada berbagai faktor yang menentukan tingkat keakuratan sistem Dapodik, misalnya kandungan informasi, kemudahan akses dan ketersediaan sistem yang seringkali belum sesuai dengan keinginan penggunanya, tidak pernah lengkapnya data sekolahan yang dimiliki oleh SMA yang ada di kota Palembang.

Sejauh ini, belum banyak penelitian terkait pemanfaatan pendekatan system Utility seperti yang dikemukakan oleh Kendall dan Kendall, 2007 (dalam Martoyo, 2015). Salah satu penelitian yang mengembangkan pendekatan system utility menjadi satu alat untuk mengevaluasi persepsi pengguna sistem yaitu dengan menggabungkan enam sudut pandang terhadap tiga dimensi persepsi pengguna terhadap sistem informasi yaitu dimensi produk (sistem informasi atau informasi yang dihasilkan oleh sistem itu sendiri), proses (bagaimana informasi itu dihasilkan), dan layanan atau service (bagaimana kualitas layanan sistem informasi ataupun infrastruktur pendukung terhadap pengguna). Penggabungan ini dilakukan agar diperoleh gambaran yang lebih menyeluruh atas persepsi pengguna terhadap sistem. Lebih lanjut, dilakukan juga identifikasi elemen evaluasi dengan meninjau ulang definisi setiap aspek dan menerjemahkannya menjadi identifikasi kualitas sistem (Martoyo, 2015).

Salah satu pendekatan evaluasi sistem dari segi efektivitas adalah pendekatan System Utility. Pendekatan yang dikemukakan oleh Kendall \& Kendall, 2007 (dalam Martoyo, 2015) ini meninjau keberhasilan implementasi sistem dari enam sudut pandang yaitu : posession Utility, Goal Utility, Place Utility, Form Utility, Time Utility, dan Actualization Utility. Pendekatan ini termasuk pada kategori efektivitas dikarenakan berusaha mengevaluasi sistem berdasarkan ekspektasi pengguna terhadap system (Akbar \& Antoni, 2019; Ariana, Azim \& Antoni 2020).

\section{Metode Penelitian}

\subsection{Desain Penelitian}

Penelitian ini dilakukan terhadap sistem DAPODIKMEN dengan Pendekatan System Utility, yang mana responden yang akan diteliti yaitu operator sekolah pada sekolah menengah atas 
negeri kota palembang. Desain penelitian dalam penelitian ini dapat dijelaskan sebagai berikut:

1. Memilih Objek dan Menentukan Permasalahan Penelitian.

2. Menentukan Evaluator/ Responden

3. Mempresentasikan Tugas Kepada Responden

4. Memberikan Tugas Kepada Responden

5. Pengisian Kuisioner dari Responden

6. Analisa Jawaban dari Responden

7. Melakukan Evaluasi

8. Membuat Laporan dari Evaluasi dan Memberikan Rekomendasi

\subsection{Data Penelitian}

Data yang digunakan dalam penelitian ini adalah data primer, yaitu data yang langsung dikumpulkan oleh peneliti dari sumber pertamanya. Di dalam penelitian diperlukan adanya data untuk mengungkap fakta sehingga penelitian dapat berhasil sesuai dengan tujuan. Data primer yang dikumpulkan berupa penyebaran kuisioner secara elektronik dengan menggunakan fasiltas pada google forms dan non elektronik melalui media survey untuk mendapatkan data (Fauzi, Dencik \& Asiati, 2019).

Menurut Sujarweni (2012) Populasi merajuk pada sekumpulan orang atau objek yang memiliki kesamaan dalam satu atau beberapa hal yang membentuk masalah pokok dalam suatu riset khusus. Populasi yang akan diteliti harus didefinisikan dengan jelas sebelum penelitian dilakukan.

Purposive Sampling merupakan sampling dimana pengambilan elemen-elemen yang dimasukkan dalam sampel dilakukan dengan sengaja, dengan catatan bahwa sampel tersebut representatif atau mewakili populasi Marzuki (2002).

Jumlah populasi dalam penelitian ini adalah 22 (Dua puluh dua) orang operator DAPODIKMEN sekolah menengah tingkat atas negeri yang ada di kota Palembang. Presentase kelonggaran yang digunakan adalah $1 \%$. Maka untuk mengetahui dalam sampel penelitian ini, berikut perhitungannya :

$$
n=\frac{22}{1+22(0,01)^{2}}=21,95
$$

Berdasarkan perhitungan sampel di atas, yang menjadi responden dalam penelitian ini adalah sebanyak 22 orang operator sekolah. Sampel diambil berdasarkan teknik probability sampling; simple random sampling, di mana peneliti memberikan peluang yang sama bagi setiap unsur (anggota) populasi untuk dipilih menjadi anggota sampel untuk dilakukan secara acak tanpa memperhatikan strata yang ada dalam populasi itu sendiri.

\subsection{Definisi Operasional dan Skala Pengukuran Variabel}

Tahapan yang dilakukan adalah menganalisis elemen-elemen pada kerangka kerja utility system, kemudian mendefinisikan sub elemen atau interpretasi setiap elemen pada kerangka kerja utility system. Pemilihan pada pendekatan utility system dilakukan dengan pertimbangan bahwa pendekatan ini memfokuskan kepada pemanfaatan sistem oleh pengguna sistem itu sendiri secara kualitatif.

Penyusunan kerangka kerja evaluasi dimulai dengan menginterpretasikan setiap aspek pada 
kerangka kerja utility system menjadi satu statemen yang terukur, dan setiap statemen diberi nomor sesuai dengan aspek yang sedang dikaji.

1. G (Goal) : dengan nomor item G1, G2, G3, G4, G5

2. PS (Possession) : dengan nomor item PS1,PS2, PS3, PS4, PS5

3. PL (Place)

: dengan nomor item PL1,PL2, PL3, PL4, PL5

4. $\mathrm{F}($ Form $)$

: dengan nomor item F1, F2, F3, F4, F5

5. $\mathrm{T}$ (Time)

: dengan nomor item T1, T2, T3, T4, T5

6. A (Actualization) : dengan nomor item A1, A2, A3, A4, A5

Kuisioner dirancang sesuai dengan kerangka kerja yang dihasilkan dari pemetaan pada proses sebelumnya. Kuisioner akan diberikan kepada operator DAPODIKMEN sekolah sesuai dengan peranan dan fungsinya.

Bentuk umum kuisioner disusun mengikuti skala pengukuran evaluasi semantik diferensial yang mengukur penilaian berdasarkan sikap responden terhadap satu kondisi. Pilihan jawaban dipetakan dalam bentuk Likert scale dengan rentang nilai 1 ('sangat tidak setuju) hingga 5 ('sangat setuju').

Pengukuran jawaban dari responden untuk persepsi pengguna sistem DAPODIKMEN ini menggunakan skala dan yang dipilih. Setelah data hasil kuisioner dikumpulkan, kemudian dilakukan pengolahan data dengan langkah-langkah sebagai berikut :

1. Menghitung rata-rata nilai skor setiap dimensi masing-masing atribut.

2. Menghitung rata-rata nilai skor setiap atribut

3. Perhitungan rata-rata dilengkapi dengan perhitungan standar deviasi untuk menguji kualitas data.

4. Menghitung kesenjangan nilai yang diperoleh dari ekspektasi dan kenyataan.

5. Memberikan ranking atas rata-rata nilai yang diperoleh

6. Melakukan analisis atas hasil yang diperoleh.

7. Mengusulkan rekomendasi berdasarkan hasil analisis dan pengamatan di lapangan.

\subsection{Alat Ukur Penelitian}

Hasil penelitian yang diambil dengan menggunakan kuesioner mendapatkan data kualitatif yang diukur berdasarkan skala likert. Menurut Sugiyono (2010:132) skala likert digunakan untuk mengukur sikap, pendapat, dan persepsi seseorang atau sekelompok orang tentang fenomena sosial. Dengan skala likert, maka variabel yang akan diukur dijabarkan menjadi indikator variabel, kemudian indikator tersebut dijadikan sebagai titik tolak untuk menyusun item-item instrumen yang dapat berupa pernyataan atau pertanyaan. Ukuran skala likert terdiri dari 5 poin, yaitu :

$\begin{array}{ll}\text { Sangat Tidak Setuju (STS) } & =1 \\ \text { Tidak Setuju (TS) } & =2 \\ \text { Ragu-ragu (R) } & =3 \\ \text { Setuju (S) } & =4 \\ \text { Sangat Setuju (SS) } & =5\end{array}$




\subsection{Sumber Jenis Data}

\section{Data Primer}

Dalam penelititan ini data primer berasal dari jawaban kuesioner yang diisi oleh operator DAPODIKMEN sekolah yang diminta menjadi responden. Para operator DAPODIKMEN sekolah yang dimaksud adalah operator yang aktif menggunakan sistem DAPODIKMEN.

2. Data Sekunder

Yaitu data yang diperoleh dari literatur buku, jurnal penelitian dan internet.

\subsection{Metode Pengumpulan Data}

Metode Angket (Kuesioner)

Angket (Kuesioner) adalah suatu cara pengumpulan data dengan menyebarkan daftar pertanyaan kepada responden, dengan harapan mereka akan memberikan respons terhadap daftar pertanyaan tersebut. Pada penelitian ini, peneliti menyebarkan kuesioner kepada responden penelitian.

\section{Uji Validitas dan Uji Reliabilitas}

Uji Validitas digunakan untuk mengetahui kelayakan butir-butir dalam suatu daftar pertanyaan dalam mendefinisikan suatu variabel. Menurut Kuncoro (2003:231) bahwa untuk menentukan validitas digunakan teknik korelasi product moment. Jika angka korelasi yang diperoleh lebih besar dari pada angka kritis maka pertanyaan tersebut valid. Jika tidak, maka instrument harus direvisi sesuai dengan keadaan data, yaitu dengan cara menambah daftar pertanyaan atau mengurangi daftar pertanyaan.

Uji reabilitas menguji seberapa koefisien satu atau seperangkat instrument pengukuran, mengukur secara konsisten suatu konsep studi kasus yang dimaksudkan untuk diukur. Reabilitas menunjukkan suatu stabilitas dan konsisten instrument pengukuran dalam mengukur konsep studi. Pengujian reabilitas setiap variabel dalam penelitian ini menggunakan koefisien cronboach's alpha dan item to total correlation yang berguna untuk memperbaiki pengukuran dengan mengeliminasi butir-butir yang kehadirannya akan memperkecil cronboach's alpha. Rules of thumb menyarankan bahwa nilai cronboach's alpha harus lebih besar $(>)$ atau sama dengan $(=) 0,6$.

\section{Ukuran Pemusatan Data}

Menurut Setiawan (2011), Salah satu aspek yang paling penting untuk menggambarkan distribusi data adalah nilai pusat data pengamatan (Central Tendency). Setiap pengukuran aritmatika yang ditujukan untuk menggambarkan suatu nilai yang mewakili nilai pusat atau nilai sentral dari suatu gugus data (himpunan pengamatan) dikenal sebagai ukuran pemusatan data (tendensi sentral). Terdapat tiga ukuran pemusatan data yang sering digunakan, yaitu:

1. Mean (Rata-rata hitung/rata-rata aritmetika)

2. Median

3. Mode

\subsection{Aplikasi DAPODIKMEN}

Menurut panduan Manual Aplikasi Dapodikmen (SMA), 2014 Bagian Perencanaan dan Penganggaran SetDitjen Dikmen, menjelaskan : 
1. Penjelasan Aplikasi

Aplikasi dapodikmen merupakan perkembangan dari aplikasi PAS (Paket Aplikasi Sekolah).

2. Tanggung jawab dan Keberhasilan Data

Berdasarkan undang-undang Republik Indonesia Nomor 11 tahun 2008 tentang Informasi dan Transaksi Elektronik, Pemanfaatan Teknologi Informasi dan Transaksi Elektronik dilaksanakan berdasarkan asas kepastian hukum, manfaat, kehati-hatian, iktikad baik, dan kebebasan memilih teknologi atau netral teknologi.

Kerahasiaan Data :

Sepanjang tidak ditentukan lain oleh undang-undang tersendiri, setiap penyelenggara sistem elektronik wajib mengoperasikan sistem elektronik yang memenuhi persyaratan.

\section{Peran Pengguna Aplikasi}

Beberapa peran terkait aplikasi dapodikmen seperti berikut:

a. Peran Kepala Sekolah

b. Peran PTK (Pendidik dan Tenaga Kependidikan)

c. Peran Peserta Didik

d. Peran Operator Sekolah adalah:

Kondisi Saat ini

Aplikasi Sistem Dapodikmen terbagi menjadi tiga bagian yaitu aplikasi Front End, aplikasi Sinkronisasi dan aplikasi Back End. (Direktorat Jenderal Pendidikan Menengah Kementerian Pendidikan dan Kebudayaan, 2014).

\section{Hasil dan Pembahasan}

\subsection{Profil Responden}

Dalam desain penelitian telah dijelaskan bahwa responden penelitian ini adalah operator sekolah pada sekolah menengah atas negeri kota palembang. Para operator sekolah ini berjumlah 22 orang sesuai dengan jumlah sekolah menengah atas negeri yang ada di kota palembang saat ini.

Berdasarkan penyebaran dari data kuesioner diperoleh respon rata-rata pengembalian kuesioner sebesar 95,65\% (22/23) untuk responden dengan status operator sekolah dan 100\% (2/2) untuk responden lainnya. Sedangkan data yang mengalami kerusakan sebanyak 1 eksemplar dan dilakukan perbaikan kembali dengan pengisian ulang terhadap kuesioner tersebut.

Adapun gambaran mengenai para responden yang menggunakan sistem DAPODIKMEN dapat dibedakan berdasarkan umur, jenis kelamin, status dan pengalaman responden dalam menggunakan komputer, sehingga bisa dianalisis tingkat kebenaran atau kevalidan dari datadata yang isi oleh para responden.

\subsection{Uji Validitas dan Reliabilitas}

Responden dalam penelitian ini adalah operator sekolah sistem DAPODIKMEN yang berlokasi di kota palembang dengan jumlah 22 responden. Uji reliabilitas instrumen dilakukan dengan melihat koefisien $\alpha$ Cronbach $>0,6$ dan Corrected item-total correlation 22 responden dengan presentase kelonggaran yang digunakan adalah $1 \%=0,537$ dari nilai rtabel. Dari 30 butir pertanyaan keseluruhan nilai Corrected item-total correlation $>0,537$, ini menyatakan semua 
pertanyaan valid.

Dari hasil pengujian Uji Reliabilitas didapat nilai cronboach's alpha 0,977 ini berarti $\alpha>0.6$ maka instrumen penelitian dikatakan reliable.

Tabel 1. Uji Reliabilitas

\begin{tabular}{cc}
\hline $\begin{array}{c}\text { Cronbach's } \\
\text { Alpha }\end{array}$ & N of Items \\
\hline $\mathbf{9 7 7}$ & $\mathbf{3 0}$ \\
\hline
\end{tabular}

\subsection{Pembahasan Penelitian}

Rekapitulasi Jawaban Responden

Dari hasil semua perhitungan jawaban responden yang telah digabungkan berdasarkan pendekatan utility system untuk variabel goal, possession, form, place, time, dan actualization maka didapatkan tabel semua aspek utility system sebagai berikut.

Tabel 2. Frequency Aspek Utility System

\begin{tabular}{lcccccc}
\hline $\begin{array}{l}\text { Aspek Utility } \\
\text { System }\end{array}$ & Mean & $\begin{array}{c}\text { Media } \\
\boldsymbol{n}\end{array}$ & Mode & $\begin{array}{c}\text { Minimu } \\
\boldsymbol{m}\end{array}$ & $\begin{array}{c}\text { Maximu } \\
\boldsymbol{m}\end{array}$ & Sum \\
\hline Goal & 4,32 & 4,0 & 4,0 & 3,0 & 5,0 & 475,0 \\
\hline Posession & 4,34 & 4,0 & 4,0 & 3,0 & 5,0 & 477,0 \\
\hline Place & 4,19 & 4,0 & 4,0 & 3,0 & 5,0 & 461,0 \\
\hline Form & 4,32 & 4,0 & 4,0 & 3,0 & 5,0 & 475,0 \\
\hline Time & 4,15 & 4,0 & 4,0 & 3,0 & 5,0 & 457,0 \\
\hline Actualization & 4,26 & 4,0 & 4,0 & 3,0 & 5,0 & 469,0
\end{tabular}

Sumber : Data yang diolah dengan IBM SPSS version 21.0 dan Microsoft office Excel 2007)

Pembahasan Hasil Tiap Variabel

Sebelum menentukan nilai mean/rata-rata, median, mode, minimum, maksimum dan total/sum hasil nilai dari setiap aspek utility sistem tentunya kita akan mencari nilai dari masing-masing pernyataan atau pertanyaan yang ada pada aspek utility system itu sendiri. Setelah didapatkan nilai pada masing-masing pernyataan atau pertanyaan maka selanjutnya dihitung nilai mean/rata-rata, median dan mode pada setiap aspek utility system Berikut ini adalah gambar grafik dari hasil perhitungan nilai mean/rata-rata dari aspek utility sistem. 


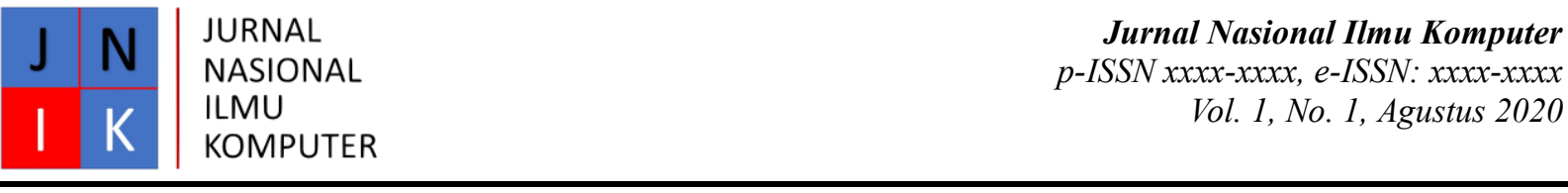

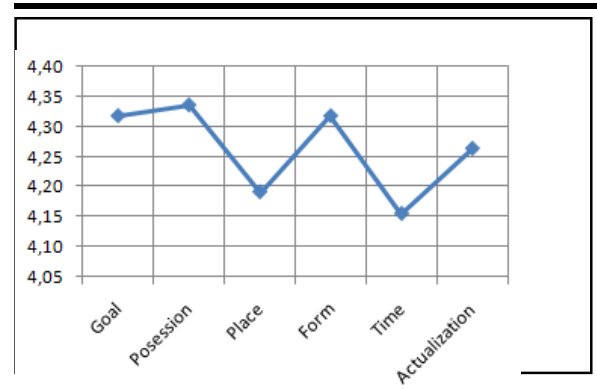

Gambar 1. Grafik nilai rata-rata aspek Utility System

1. Goal utility dengan nilai rata-rata 4.32, nilai median 4 dan nilai mode 4 jadi dapat disimpulkan berdasarkan jawaban responden yang diukur berdasarakan skala likert sebagian besar responden menyatakan setuju dengan pernyataan :

a. Sistem DAPODIKMEN mempermudah dalam proses/melihat data pendidikan SMA.

b. Sistem DAPODIKMEN mempermudah pekerjaan menginput data SMA/sekolah.

c. Sistem DAPODIKMEN menghasilkan data yang tepat dan waktu yang cepat dari hasil kerja operator.

d. Sistem DAPODIKMEN dibutuhkan dalam penyiapan kegiatan belajar mengajar disekolah.

e. Sistem DAPODIKMEN dapat membantu dalam efisiensi kegiatan belajar mengajar disekolah.

Berdasarkan kajian atas pendekatan utility system untuk mengevaluasi persepsi pengguna sistem DAPODIKMEN berdasarkan evaluasi dari sudut pandang goal dapat dinyatakan bahwa kebutuhan sistem DAPODIKMEN memiliki peranan yang berarti bagi Sekolah Menengah Atas Negeri Kota Palembang dalam mendukung kinerja dan pencapaian tujuan sekolah.

2. Posession utility mencapai nilai rata-rata 4.34, nilai median 4 dan nilai mode 4 jadi dapat disimpulkan berdasarkan jawaban responden yang diukur berdasarakan skala Likert menunjukkan bahwa responden menyatakan setuju dengan pernyataan:

a. Informasi dari Sistem DAPODIKMEN dapat dilihat oleh semua/ Stakeholder.

b. Informasi dari Sistem DAPODIKMEN dibutuhkan kepala sekolah.

c. Informasi dari Sistem DAPODIKMEN dibutuhkan komite sekolah.

d. Informasi dari Sistem DAPODIKMEN dibutuhkan Disdikpora kota Palembang.

e. Informasi dari Sistem DAPODIKMEN lebih akurat dan tepat sasaran.

Jadi berdasarkan evaluasi dari sudut pandang Posession dapat dinyatakan bahwa keluaran sistem DAPODIKMEN sudah tepat pada sasaran dan dibutuhkan oleh fungsi tertentu pada Sekolah Menengah Atas Negeri Kota Palembang, Stakeholder dan Disdikpora.

3. Place utility dari sistem DAPODIKMEN mendapatkan nilai rata-rata 4.19 serta nilai median 4 dan nilai mode 4 jadi dapat disimpulkan berdasarkan jawaban responden yang diukur berdasarakan skala Likert ini juga menunjukkan bahwa responden menyatakan setuju dengan pernyataan :

a. Sistem DAPODIKMEN dapat diakses dengan mudah oleh operator.

b. Hasil dari Sistem DAPODIKMEN dapat diakses oleh semua yang berhubungan/ berkepentingan.

c. Sistem DAPODIKMEN dapat diakses dari luar Sekolah. 
d. Sistem DAPODIKMEN dapat diakses selama 24 jam.

e. Output Sistem DAPODIKMEN dapat didistribusikan pada pihak yang berkepentingan. Jadi berdasarkan evaluasi persepsi pengguna sistem DAPODIKMEN dari sudut pandang Place dapat dinyatakan bahwa ruang lingkup distribusi informasi sistem DAPODIKMEN dapat tersebar dengan baik di lingkungan atau pengguna informasi pada Sekolah Menengah Atas Negeri Kota Palembang, kementerian dan pihak lain yang berkepentingan.

4. Form utility dari sistem DAPODIKMEN mendapatkan nilai 4.32, nilai median 4 dan nilai mode juga 4 jadi dapat disimpulkan berdasarkan jawaban responden yang diukur berdasarakan skala Likert sebagian besar responden menyatakan setuju dengan pernyataan :

a. Output sistem DAPODIKMEN mudah di simpan dalam bentuk file.

b. Output sistem DAPODIKMEN dapat di konversi ke bentuk file.pdf.

c. Output sistem DAPODIKMEN dapat didistribusikan dengan mudah dalam benuk file attachment (email)

d. Output sistem DAPODIKMEN yang ditampilkan mudah di pahami sesuai dengan kebutuhan pihak yang berkepentingan.

e. Output sistem DAPODIKMEN tidak memiliki kesalahan baik dari segi perhitungan maupun isi data.

Berdasarkan kajian atas pendekatan utility system untuk mengevaluasi persepsi pengguna sistem DAPODIKMEN berdasarkan evaluasi dari sudut pandang Form utility dapat dinyatakan bahwa keluaran Sistem DAPODIKMEN dapat ditampilkan dalam berbagai bentuk, Kemudahan distribusi keluaran sistem DAPODIKMEN dan konten informasi yang ditampilkan pada keluaran sistem DAPODIKMEN mudah dimengerti.

5. Time utility dengan nilai rata-rata 4.15 , nilai median 4 dan nilai mode 4 jadi dapat disimpulkan berdasarkan jawaban responden yang diukur berdasarakan skala Likert sebagian besar responden menyatakan setuju dengan pernyataan :

a. Output sistem DAPODIKMEN yang dihasilkan tepat waktu.

b. Output Sistem DAPODIKMEN mudah diakses saat dibutuhkan.

c. Sistem DAPODIKMEN dapat di akses dalam waktu singkat .

d. Respon time sistem DAPODIKMEN baik.

e. Waktu pengiriman data DAPODIKMEN sama dengan kalender sekolah.

Jadi dapat dinyatakan bahwa keluaran sistem DAPODIKMEN sudah menghasilkan keluaran yang tepat pada waktu yang sudah diinginkan oleh pengguna sistem pada Sekolah Menengah Atas Negeri Kota Palembang.

6. Actualization utility dengan nilai 4.26 nilai median 4 dan nilai mode juga 4 jadi dapat disimpulkan berdasarkan jawaban responden yang diukur berdasarakan skala Likert sebagian besar responden menyatakan setuju dengan pernyataan :

a. Kepala sekolah sudah mengenal akan keberadaan sistem.

b. Output sistem DAPODIKMEN yang ditampilkan memuat data yang akurat dan terkini.

c. Output sistem DAPODIKMEN mudah dipahamai untuk membuat keputusan.

d. Output sistem DAPODIKMEN bermanfaat untuk membuat keputusan.

e. Sekolah dapat memanfaatkan isi informasi DAPODIKMEN yang dikeluarkan oleh sistem untuk memberikan rekomendasi perbaikan.

Berdasarkan kajian atas pendekatan utility system untuk mengevaluasi persepsi pengguna 
sistem DAPODIKMEN berdasarkan evaluasi dari sudut pandang Actualization utility dapat dinyatakan bahwa bahwa sistem DAPODIKMEN sudah diperkenalkan dan dapat digunakan oleh pengambil keputusan pada Sekolah Menengah Atas Negeri Kota Palembang atau unit-unit lainnya.

Pernyataan diatas menunjukkan kesimpulan mengenai hasil dari tiap aspek variabel utility system. Nilai rata-rata tertinggi dari aspek variabel utility system adalah aspek Posession utility dengan nilai tertinggi 4.34 ini menunjukkan operator sekolah setuju bahwa keluaran sistem DAPODIKMEN sudah tepat.

Pembahasan Hasil Akhir

Untuk menentukan hasil akhir rata-rata yaitu dengan cara menambahkan rata-rata seluruh aspek utility sistem dari sistem DAPODIKMEN yaitu goal, possession, form, place, time, dan actualization dan kemudian dibagi dengan jumlah aspek utility sistem dari sistem DAPODIKMEN dan didapatkan hasil akhir pencapaian persepsi pengguna sistem DAPODIKMEN sebesar 4,2636 yang menjelaskan keberadaan sistem DAPODIKMEN di Sekolah Menengah Atas Negeri Kota Palembang adalah menyatakan setuju efektif dan didapatkan gambar rating scale rata-rata, sebagai berikut.

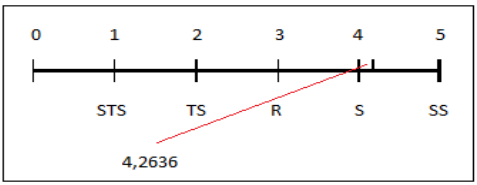

Gambar 2. Rating Scale rata-rata

\section{Kesimpulan}

Berdasarkan hasil pengukuran tingkat persepsi pengguna sistem DAPODIKMEN terhadap 22 sekolah menengah atas negeri kota palembang didapatkan nilai persepsi pengguna sistem DAPODIKMEN sebesar 4,2636 yang menyatakan keberadaan sistem DAPODIKMEN di sekolah menengah atas negeri kota palembang adalah efektif atau setuju. Dengan keberadaan sistem DAPODIKMEN pada sekolah menengah atas negeri kota palembang yang dinyatakan setuju maka dapat disimpulkan bahwa keberadaan sistem DAPODIKMEN terbukti dapat membantu dalam penyediaan data sekolah yang lengkap, akurat dan mudah diakses.

\section{Referensi}

Akbar, M., \& Antoni, D. (2019). E-supply chain management value concept for the palm oil industry. Jurnal Sistem Informasi, 15(2), 15-29.

Ariana, S., Azim, C., \& Antoni, D. (2020). Clustering of ICT human resource capacity in the implementation of E-government in expansion area: A case study from Pali regency. Cogent Business \& Management, 7(1), 1754103.

Direktorat Jenderal Pendidikan Menengah Kementerian Pendidikan dan Kebudayaan. (2014). Roadmap pengembangan sistem Dapodikmen tahun 20142019. (http://dapo.dikmen.kemdikbud.go.id/portal/web/docs/ Roadmap Dapodikmen. pdf) Diakses tanggal 3 Febuari 2016

Fauzi, F., Dencik, A. B., \& Asiati, D. I. (2019). Metodologi Penelitian Untuk Manajemen dan Akuntansi. Jakarta: Salemba Empat. 
Kuncoro. (2003). Pengertian uji validitas. diakses tanggal 24 Juli 2014. http://elektronika.unp.ac.id/wpcontent/uploads/2008/03/nelda_andri_makasemnas2008.pdf

Manual Aplikasi Dapodikmen (SMA). (2014). Bagian perencanaan dan penganggaran Setditjen Dikmen (http://dapo.dikmen.kemdikbud.go.id/ portal/web/docs/dokSMA.pdf). Diakses tanggal 10 Febuari 2016

Martoyo., Usama, W., \& Falahah. (2015). Kajian evaluasi usability dan utility pada Situs Web. (http://is.its.ac.id/pubs/oajisindex.php/ file/download_file/ 1605.) Diakses tanggal 12 Febuari 2016

Marzuki. (2002). Metodologi Riset. BPFE UII, Yogyakarta

Setiawan., \& Ade. (2011). Ukuran pemusatan data: Mean - Median - Mode (http://www.smartstat.info/statistika/statisika-deskriptif/ukuran pemusatan-data-mean-medianmode.html). Diakses tanggal 27 April 2016

Sugiyono. (2010). Metode penelitian bisnis. Jakarta: Salemba Empat

Sujarweni, V.W. ( 2012). Statistik untuk penelitian, Graha Ilmu, Yogyakarta

\section{Copyrights}

Copyright for this article is retained by the author(s), with first publication rights granted to the journal.

This is an open-access article distributed under the terms and conditions of the Creative Commons Attribution license (http://creativecommons.org/licenses/by/4.0/) 